\title{
Efficacy of intravenous lidocaine in improving post-operative nausea, vomiting and early recovery after laparoscopic gynaecological surgery
}

\author{
TAO WANG ${ }^{1 *}$, HUI LIU ${ }^{2 *}$, JIAN HONG SUN $^{1}$, LIN WANG $^{1}$ and JIAN YOU ZHANG \\ Departments of ${ }^{1}$ Anesthesia and ${ }^{2}$ Endocrinology, Affiliated Hospital of Yangzhou University, \\ Yangzhou, Jiangsu 225000, P.R. China
}

Received August 21, 2018; Accepted February 28, 2019

DOI: $10.3892 /$ etm.2019.7497

\begin{abstract}
Post-operative nausea and vomiting (PONV) is a major peri-operative complication. It has numerous adverse consequences that seriously affect the post-operative recovery of patients. The aim of the present study was to investigate the efficacy of intravenous lidocaine in improving PONV and recovery after laparoscopic gynaecological surgery. A total of 40 patients were randomly assigned to 2 groups: Group L (lidocaine group) and Group C (control group). The patients in Group $\mathrm{L}$ received intravenous lidocaine throughout the operation, while patients in Group $\mathrm{C}$ were given a saline infusion. Vital signs, recovery time, extubation time, dosage of remifentanil, first flatus time and defecation time of each patient were recorded. The incidence of PONV after surgery was also recorded. The recovery of the patients was evaluated by using the quality of recovery score (QoR-40). The total dose of remifentanil was significantly lower in Group $\mathrm{L}(\mathrm{P}<0.05)$. However, the recovery time and extubation time were shorter in Group $\mathrm{C}(\mathrm{P}<0.05)$. The first flatus time and defecation time were longer in Group $\mathrm{C}(\mathrm{P}<0.05)$. The mean arterial pressure and heart rate in Group $\mathrm{L}$ were lower and more stable $(\mathrm{P}<0.05)$. At $6 \mathrm{~h}$ after surgery, the incidence of PONV was significantly lower in Group L vs. that in Group C $(\mathrm{P}<0.05)$. The QoR-40 score in Group $\mathrm{C}$ was significantly lower at 1 and 3 days after the operation compared with that in Group $\mathrm{C}$ $(\mathrm{P}<0.05)$. In conclusion, intravenous lidocaine administered to patients undergoing laparoscopic gynaecological surgery may reduce PONV and supports their early recovery [trial
\end{abstract}

Correspondence to: Dr Jian You Zhang, Department of Anesthesia, Affiliated Hospital of Yangzhou University, 368 Middle HanJiang Road, HanJiang, Yangzhou, Jiangsu 225000, P.R. China

E-mail: zjy_oracle@163.com

*Contributed equally

Key words: lidocaine, laparoscopy, post-operative nausea and vomiting, anaesthesia, intravenous registration number in Chinese Clinical Trial Registry: ChiCTR-IOR-17010782 (March 5, 2017)].

\section{Introduction}

Rapid progress has been made in the development of minimally invasive surgery. Laparoscopic surgery has the advantages of less pain, more rapid recovery and less discomfort (1), and increasing numbers of patients are opting for this method. However, laparoscopic surgery is one of the high-risk surgical factors for post-operative nausea and vomiting (PONV) (2). A variety of studies have indicated that the incidence of PONV is $\sim 30 \%$ after general anaesthesia and $50-70 \%$ after laparoscopic surgery $(3,4)$. Females are more susceptible to PONV than males (5). An estimated 71-80\% of patients suffer from PONV after general anaesthesia for gynaecological laparoscopy (6). Thus, PONV is one of the most common complaints after laparoscopic surgery together with post-operative pain. PONV is a distressing symptom after general anaesthesia and may increase patient discomfort and clinical problems, including disruption of the surgical wound, dehydration, electrolyte imbalance, aspiration pneumonia and haemorrhage $(7,8)$. Furthermore, it may prolong recovery time, increase hospital costs and delay patient discharge (9). Therefore, reducing the incidence of PONV is conducive to the recovery of patients.

Numerous methods and drugs may prevent PONV, including 5-HT3 receptor antagonists, dopamine receptor antagonists, neurokinin-1 receptor antagonists, dexamethasone and propofol (10). However, these drugs are expensive or have numerous adverse effects. Peri-operative intravenous lidocaine is beneficial to the recovery of patients and has been widely used in clinical surgery (11). Clinical trials have indicated that intravenous lidocaine markedly reduces the incidence of PONV (12). Lidocaine has well-established analgesic, anti-hyperalgesic and anti-inflammatory characteristics (13). Certain studies have indicated that lidocaine accelerates the restoration of bowel function after surgery, which may be attributed to its anti-inflammatory effect. The favourable effects of lidocaine infusion include reduction of nausea and vomiting, pain scores, the duration of post-operative ileus and 
the duration of hospital stay according to a clinical trial on colon surgery (14). McKay et al (15) did not obtain the same positive results in a previous study regarding ambulatory surgery. In that study, lidocaine only reduced the consumption of narcotics and maintained a temporary reduction in pain scores (15). The reduction of post-operative opioid consumption and the anti-inflammatory properties of lidocaine may be involved in the improvement of opioid-induced bowel dysfunction, but the results of studies are contradictory, with certain studies supporting the hypothersis $(16,17)$ while another does not (18). Another study demonstrated that intravenous lidocaine did not improve the opioid consumption or nausea and vomiting in patients who underwent open abdominal hysterectomy (19). However, the effect of pre-operative and intra-operative lidocaine infusion on PONV and quality of recovery in gynaecological laparoscopy surgery has remained to be investigated. Instead of the length of hospital stay, the quality of recovery score (QoR-40) (20) has become the most widely used measure of patient-assessed quality of recovery after surgery, as it is highly sensitive to clinical changes, valid, reliable, responsive and simple to use (21). In the present study, the effect of lidocaine infusion on nausea, vomiting and QoR-40 after gynaecological laparoscopic surgery was evaluated.

\section{Materials and methods}

Research subjects. The present study was approved by the ethics committee of the Affiliated Hospital of Yangzhou University (Yangzhou, China) and all patients provided written informed consent. According to a preliminary experiment, the required sample size was calculated and it was determined that a minimum of 20 patients were needed in each group ( $\alpha$ error of 0.05 and $\beta$ error of 0.2 ). Thus, a total of 40 patients aged 30-50 years with an American Society of Anaesthesiologists' physical status of I-II (22) who were scheduled for elective laparoscopic gynaecological surgery for ovarian and uterine disease were enrolled. All patients were randomly assigned to two groups, namely the lidocaine group (Group L: Age, 41.1 \pm 7.4 years) and the control group (Group C: Age, $40.6 \pm 8.3$ years). Subjects were randomized with the aid of SPSS statistical analysis software (version 13; SPSS, Inc., Chicago, IL, USA) to receive one of two treatments in a double-blinded manner. The patients and anaesthesia providers were blinded with regard to the study group allocation throughout the study period. The solutions for injection/infusion were prepared by an independent researcher. The solution administered to Group L consisted of $1 \%$ lidocaine (China Resources Shuanghe Pharmaceutical Co., Ltd., Beijing, China) in coded $50-\mathrm{ml}$ syringes, and the solution administered to Group C consisted of an equal volume of saline.

Inclusion and exclusion criteria. Patients with the following characteristics were excluded from the study: Cardiovascular diseases, metabolic diseases, renal diseases, liver diseases, neurological disorders, acid-base balance electrolyte disorders, shock, pregnancy, history of tobacco use, history of PONV, pre-existing disorders of the gastrointestinal tract, use of anti-emetics within $48 \mathrm{~h}$ prior to surgery, chronic use of anti-cholinergic medication or chronic treatment with opioids, and an operation time of $<30 \mathrm{~min}$ or $>90 \mathrm{~min}$. All operations were performed in the morning, were the first surgeries that day and followed a standardized procedure without additional procedures including irrigation, laparotomy and blood transfusion. Surgery and nursing were performed by the same team. All patients were enrolled between April and August 2017.

Anesthesia method. Patients fasted after midnight the night prior to surgery, and $30 \mathrm{~min}$ prior to the induction of anaesthesia, they were orally pre-medicated with midazolam (0.04 mg/kg; Jiangsu Nhwa Pharmaceutical Co., Ltd., Xuzhou, China) and scopolamine $(0.3 \mathrm{mg}$; Guangzhou Baiyunshan Guanghua Pharmaceutical Co., Ltd., Guangzhou, China). Immediately prior to the induction of anaesthesia, the patients in Group $\mathrm{L}$ received an intravenous bolus injection of $1.5 \mathrm{mg} / \mathrm{kg}$ lidocaine. In Group L, the lidocaine infusion was continued at a rate of $2 \mathrm{mg} / \mathrm{kg} / \mathrm{h}$ throughout the operation, and patients were transferred to the post-anaesthesia care unit after surgery. The patients in the control group were given a saline infusion administered in a similar manner. Prior to the induction of anaesthesia, the patients' electrocardiogram, heart rate, and oxygen saturation were monitored continuously, and non-invasive arterial blood pressure was recorded at 5-min intervals throughout the procedure. For anaesthetic induction, $2 \mathrm{mg} / \mathrm{kg}$ propofol (AstraZeneca UK Limited, London, UK) and $4 \mu \mathrm{g} / \mathrm{kg}$ fentanyl (Yichang Renfu Pharmaceutical Co., Ltd., Yichang, China) were intravenously administered prior to tracheal intubation. In each of the two groups, tracheal intubation was facilitated with $0.2 \mathrm{mg} / \mathrm{kg}$ cis-atracurium (Jiangsu Hengrui Pharmaceutical Co., Ltd., Lianyungang, China), and cis-atracurium was also used for intra-operative muscle relaxation in all patients. Full muscle relaxation was maintained during surgery. Anaesthesia was maintained with $70-90 \mu \mathrm{g} / \mathrm{kg} / \mathrm{min}$ propofol and 0.2-0.5 $\mu \mathrm{g} / \mathrm{kg} / \mathrm{min}$ remifentanil (Yichang Renfu Pharmaceutical Co., Ltd.). During surgery, maintenance doses of anaesthetics were adjusted to maintain bispectralindex (BIS) within 40-60 in each group. Lactated Ringer's solution (8 ml/kg/h; China Resources Shuanghe Pharmaceutical Co., Ltd.) was infused throughout the surgery.

Record indicator. Mean arterial pressure, heart rate and oxygen saturation were recorded prior to the operation, at the time of intubation, during pneumoperitoneum, at the time of extubation, at $1 \mathrm{~min}$ after extubation and at $5 \mathrm{~min}$ after extubation. The anaesthesia time, operating time, pneumoperitoneum time, recovery time, extubation time, dosage of remifentanil, first flatus time, defecation time and length of hospital stay were recorded for each patient. The Ramsay sedation scale (RSS) score (23) was recorded at $1 \mathrm{~min}, 5 \mathrm{~min}$ and $30 \mathrm{~min}$ after extubation.

The incidence of PONV, the nausea score and the use of anti-emetics at 1, 6 and $24 \mathrm{~h}$ after surgery were also recorded. Pain scores were assessed using the visual analogue scale (VAS) (24) every $6 \mathrm{~h}$ until $48 \mathrm{~h}$ after the operation. The recovery of the patients was evaluated by using the QoR-40 at 1 day prior to the operation and at 1,3 and 5 days after the operation.

According Eberhart et al (25), the severity of PONV during the $24 \mathrm{~h}$ after surgery was divided into four categories: None 
(absence of nausea and vomiting), mild (the patient suffered only mild nausea), moderate (the patient suffered 1-2 emetic episodes or moderate or severe nausea without exogenous stimulus and anti-emetics were required), and severe (the patient vomited at least once or experienced nausea at least twice, and anti-emetics were required at least once).

The QoR-40 contains 40 items measuring five aspects of patient recovery: Psychological support ( 7 items), physical comfort (12 items), emotional wellbeing (9 items), physical independence (5 items) and pain (7 items) (17). Each item is divided into five levels (for positive items: 1, none of the time; 2 , some of the time; 3 , often; 4 , most of the time; and 5; all of the time. For negative items, the scoring was reversed). The individual scores are then added up and the resulting QoR-40 scores range from 40 (extremely poor quality of recovery) to 200 (excellent quality of recovery), with a higher QoR-40 score indicating a better recovery.

At 1 day prior to surgery, the QoR-40 instrument was explained to the patients. After they understood the meaning of the questionnaire, the QoR-40 scores were evaluated and recorded as the pre-operative baseline health status at day 0 (D0) by the assigned medical professional. QoR-40 scores were also recorded at the same time of day at 1 day post-surgery (D1), D3 and D5 by the assigned medical professional.

Statistical analysis. The major results are expressed as the mean \pm standard deviation, the median (range) or the number of patients. Student's t-test was used to compare continuous variables between the groups. The $\chi^{2}$ test or Fisher's exact test was used for categorical variables. Statistical analysis was performed using SPSS 13.0 for Windows (SPSS, Inc.).

\section{Results}

General information. A total of 45 patients were initially recruited to the current study, but 5 patients were excluded. The remaining 40 patients were subsequently allocated to the two equally sized groups and completed the study. The data from these patients were used in the analysis. No significant differences were observed between the two groups in terms of age, body weight or body height. Intraoperative data, including the duration, the $\mathrm{CO}_{2}$ pressure, the length of anaesthesia and pneumoperitoneum were similar between the two groups (Table I).

Peri-operative remifentamil dose, mean arterial pressure and heart rate are lower in the lidocaine group. The total dose of remifentanil administered peri-operatively to patients in the lidocaine group was significantly lower than that given to the saline group: $472.5 \pm 134.2 \mu \mathrm{g}$ (saline) vs. $167.5 \pm 94.9 \mu \mathrm{g}$ $(\mathrm{P}<0.001)$. Despite the decreased use of remifentanil, the mean arterial pressure and heart rate at the time-points T1-T5 were lower in the lidocaine group than those in the saline group (Figs. 1 and 2).

Patients in Group C recover quickly compared with those in Group $L$. The recovery and extubation times were shorter in Group C than they were in Group L (Table II). The first flatus time (1,752 $\pm 342 \mathrm{~min})$ and the defecation time (1,972 $\pm 363 \mathrm{~min})$
Table I. Patient and surgical data.

\begin{tabular}{lccc}
\hline & $\begin{array}{c}\text { Group } \\
\text { Parameter }\end{array}$ & $\begin{array}{c}\text { Group L } \\
(\mathrm{n}=20)\end{array}$ & P-value \\
\hline Age (years) & $40.6 \pm 8.3$ & $41.1 \pm 7.4$ & 0.826 \\
Weight (kg) & $59.1 \pm 5.1$ & $58.2 \pm 4.9$ & 0.552 \\
Body height (cm) & $162.3 \pm 3.8$ & $161.4 \pm 3.1$ & 0.412 \\
Surgery duration (min) & $54.9 \pm 20.7$ & $53.2 \pm 18.5$ & 0.792 \\
$\begin{array}{l}\text { Duration of anaesthesia } \\
\text { (min) }\end{array}$ & $59.4 \pm 21.8$ & $59.9 \pm 16.7$ & 0.936 \\
Duration of & & & \\
pneumoperitoneum (min) & & & \\
\hline
\end{tabular}

Values are expressed as the mean \pm standard deviation. There were no significant differences between the groups. L, lidocaine; C, control.

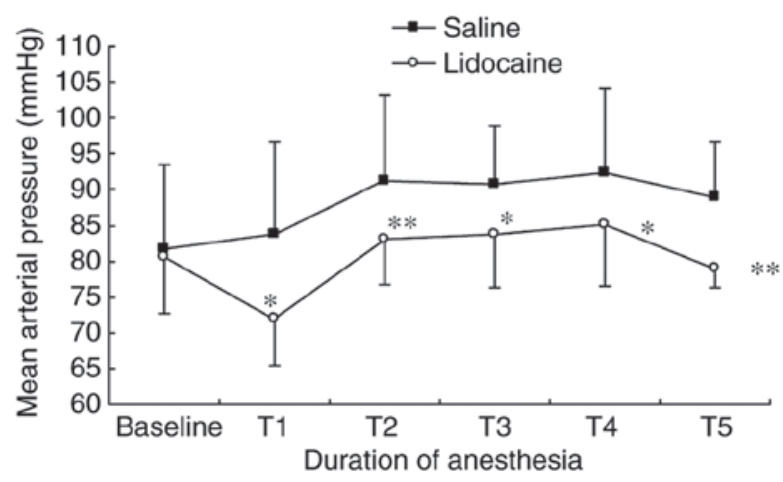

Figure 1. Mean arterial pressure changes during anaesthesia. The differences between the two groups were statistically significant at $\mathrm{T} 1, \mathrm{~T} 2, \mathrm{~T} 4$ and $\mathrm{T} 5$. ${ }^{*} \mathrm{P}<0.05 ;{ }^{* *} \mathrm{P}<0.001$ compared with saline group. $\mathrm{T} 1$, endotracheal intubation; T2, pneumoperitoneum; T3, extubation; T4, 1 min after extubation; T5, 5 min after extubation.

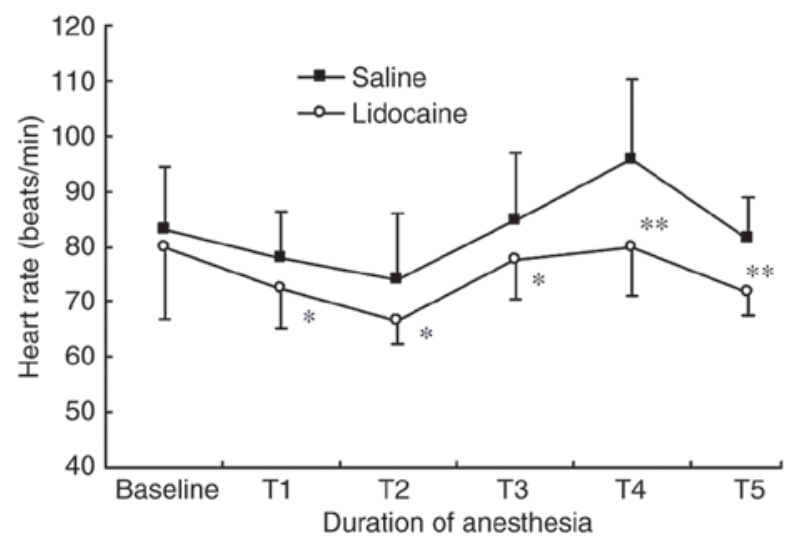

Figure 2. Heart rate changes during anaesthesia. The differences between the two groups were statistically significant at T1, T2, T4 and T5. ${ }^{*} \mathrm{P}<0.05$; ${ }^{* *} \mathrm{P}<0.001$ compared with saline group. $\mathrm{T} 1$, endotracheal intubation; $\mathrm{T} 2$, pneumoperitoneum; T3, extubation; T4, 1 min after extubation; T5, 5 min after extubation.

in Group C were longer than those in Group L $(1,452 \pm 273$ and $1,664 \pm 353 \mathrm{~min}$, respectively), but the length of the hospital stay was not significantly shorter in Group L ( $\mathrm{P}=0.32$; Table II). 
Table II. Peri-operative parameters.

\begin{tabular}{lccr}
\hline & $\begin{array}{c}\text { Group C } \\
(\mathrm{n}=20)\end{array}$ & $\begin{array}{c}\text { Group L } \\
(\mathrm{n}=20)\end{array}$ & P-value \\
\hline Parameter & $7.4 \pm 4.3$ & $11.7 \pm 4.9$ & 0.005 \\
Recovery time (min) & $12.1 \pm 3.8$ & $\begin{array}{c}16.8 \pm 3.2 \\
\text { Extubation time (min) }\end{array}$ & $<0.001$ \\
Peri-operative & $472.5 \pm 134.2$ & $167.5 \pm 94.9$ & $<0.001$ \\
remifentanil usage ( $\mu \mathrm{g})$ & & & \\
First flatus time (min) & $1,752 \pm 342$ & $1,452 \pm 273$ & 0.004 \\
Defecation time (min) & $1,972 \pm 363$ & $1,664 \pm 353$ & 0.009 \\
Discharge time (days) & $7.2 \pm 1.8$ & $6.7 \pm 1.3$ & 0.325 \\
\hline
\end{tabular}

Values are expressed as the mean \pm standard deviation. There were no significant differences between the groups. L, lidocaine; C, control.

Table III. Details regarding PONV.

\begin{tabular}{|c|c|c|c|}
\hline Parameter & $\begin{array}{c}\text { Group C } \\
(\mathrm{n}=20)\end{array}$ & $\begin{array}{l}\text { Group L } \\
(\mathrm{n}=20)\end{array}$ & P-value \\
\hline \multicolumn{4}{|c|}{$\begin{array}{l}\text { Patients with symptoms of } \\
\text { PONV at specific time-points (h) }\end{array}$} \\
\hline 1 & $7(35)$ & $4(20)$ & 0.288 \\
\hline 6 & $10(50)$ & $4(20)$ & 0.047 \\
\hline 24 & $2(10)$ & $1(5)$ & 0.999 \\
\hline \multicolumn{4}{|c|}{$\begin{array}{l}\text { Nausea (none/mild/moderate/ } \\
\text { severe) at specific time-points (h) }\end{array}$} \\
\hline 1 & $13 / 5 / 2 / 0$ & $16 / 3 / 1 / 0$ & 0.288 \\
\hline 6 & $10 / 6 / 3 / 1$ & $16 / 3 / 1 / 0$ & 0.047 \\
\hline 24 & $18 / 2 / 0 / 0$ & $19 / 1 / 0 / 0$ & 0.999 \\
\hline Anti-emetics usage (\%) & $8(40)$ & $3(15)$ & 0.077 \\
\hline
\end{tabular}

Values are expressed as $\mathrm{n}(\%)$. L, lidocaine; C, control; PONV, post-operative nausea and vomiting.

Table IV. Quality of recovery score in the two groups.

\begin{tabular}{lccc}
\hline Parameter & $\begin{array}{c}\text { Group C } \\
(\mathrm{n}=20)\end{array}$ & $\begin{array}{c}\text { Group L } \\
(\mathrm{n}=20)\end{array}$ & P-value \\
\hline 1 day prior to operation & $191.2 \pm 3.8$ & $191.4 \pm 3.4$ & 0.862 \\
1 day post-operatively & $166.3 \pm 8.2$ & $173.0 \pm 9.8$ & 0.025 \\
3 days post-operatively & $179.5 \pm 5.9$ & $183.3 \pm 6.5$ & 0.046 \\
5 days post-operatively & $189.2 \pm 4.3$ & $189.3 \pm 5.6$ & 0.949 \\
\hline
\end{tabular}

Values are expressed as the mean \pm standard deviation. L, lidocaine; C, control.

PONV incidence is similar in the two groups. There were no significant differences in the incidence of PONV between the groups at 1 and $24 \mathrm{~h}$ after surgery; however, the incidence of PONV was significantly lower at $6 \mathrm{~h}$ after surgery in Group L compared with that in Group C. The severity of PONV was

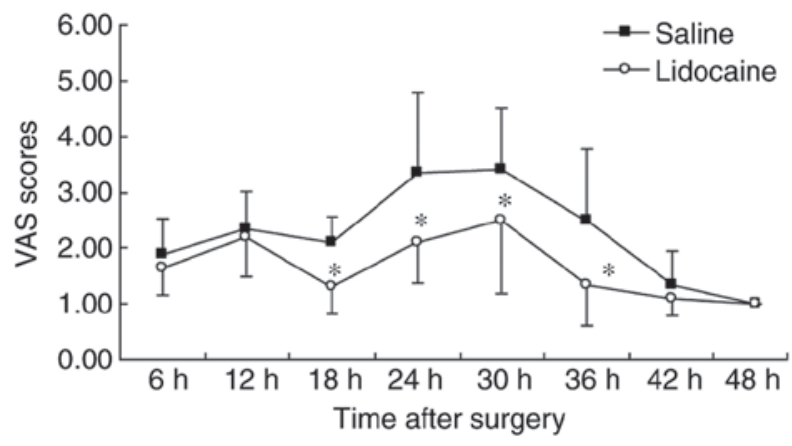

Figure 3. Mean VAS pain scores after surgery. Pain was reported on a $100-\mathrm{mm}$ VAS, with $0 \mathrm{~mm}$ indicating no pain and $100 \mathrm{~mm}$ the worst pain imaginable. Mean VAS pain scores were recorded every $6 \mathrm{~h}$ from $6 \mathrm{~h}$ to $48 \mathrm{~h}$ after surgery. $* \mathrm{P}<0.05$ compared with the saline group. VAS, visual analog scale.

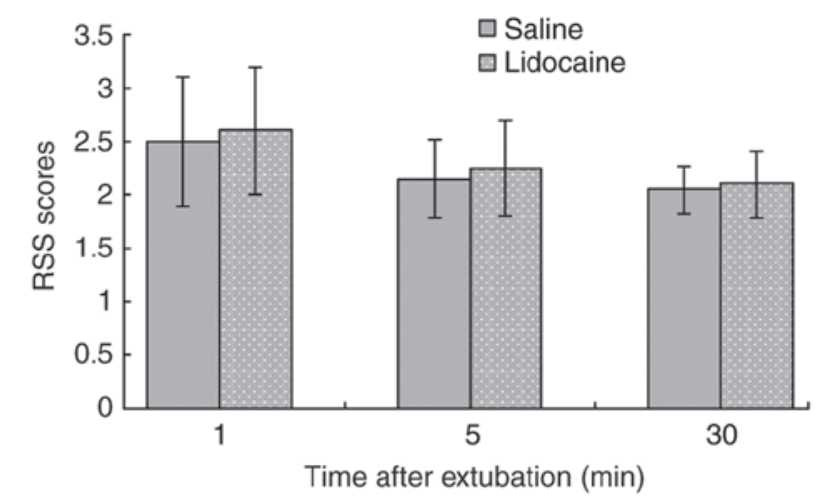

Figure 4. Mean RSS scores after surgery. Mean RSS scores at 1, 5, 30 min after extubation. There were no significant differences between the groups at any of the time-points. RSS, Ramsay sedation scale.

not significantly different between the groups at any given time-point. Compared to Group C, fewer anti-emetic agents were used in Group L (Table III).

Patients in Group $C$ have a faster recovery time compared with those in Group L. The VAS scores in Group L were lower compared with those in Group C at 18, 24, 30 and $36 \mathrm{~h}$ after the operation. The RSS score was not significantly different between the groups at any time-point after extubation (Figs. 3 and 4). The QoR-40 scores of Group C were significantly lower compared with those of Group L at 1 and 3 days after the operation. No significant difference was observed at 5 days (Table IV).

\section{Discussion}

PONV more frequently occurs in cases with the presence of peri-operative haemodynamic instability and in female patients, non-smokers and patients with past histories of PONV or motion sickness (5). General anaesthesia with inhalational anaesthetics or nitrous oxide with the peri-operative use of opioids may increase nausea and vomiting (26). Laparoscopic gynaecological surgery is more likely to cause PONV (2), which led to the choice of this type of surgery for the present study. According to a previous study, there was no significant difference in the incidence of PONV when the duration of 
anaesthesia was 30-90 min. The incidence increased significantly after $90 \mathrm{~min}$ (27). Therefore, patients with a duration of anaesthesia between 30 and 90 min were selected for the present study.

Lidocaine is a commonly used local anaesthetic and anti-arrhythmic drug. It reversibly inhibits the generation and propagation of action potentials by blocking sodium currents, resulting in sedative and antalgic effects (28). A study by Kaba et al (16) indicated that the induction of anaesthesia with an intravenous administration of $1.5 \mathrm{mg} / \mathrm{kg}$ lidocaine and the maintenance of anaesthesia with $2.0 \mathrm{mg} / \mathrm{kg} / \mathrm{h}$ lidocaine until the end of the surgery result in plasma concentrations of lidocaine reaching $2.4 \pm 0.6 \mu \mathrm{g} / \mathrm{ml}$, which is effective for pain control. It is lower than the toxic plasma concentration of lidocaine $(5 \mu \mathrm{g} / \mathrm{ml})$ (29). Therefore, the manner of administration of lidocaine in the present study was safe.

The present study indicated that the use of opioids in the lidocaine group was less than that in the control group, consistent with the results of a previous study (30). Intravenous lidocaine may inhibit the discharge of neurons and fibres by blocking sodium channels (31) and reduce the threshold of peripheral noxious stimulation to achieve analgesic and pain desensitization effects (32). In addition, intravenous lidocaine may inhibit G protein-coupled receptors, N-methyl-D-aspartate receptors, the release of inflammatory factors and the function of leukocytes. Therefore, it has anti-inflammatory, analgesic, anti-hyperalgesic and immune regulatory effects (33-36). A previous study indicated that the major mechanism of the anaesthetic action of propofol is the inhibition of sodium channels in the central nervous system, and lidocaine is able to enhance the effect of propofol by also inhibiting sodium channels (37). The present study indicated that the blood pressure and heart rate were lower but more consistent in the lidocaine group than they were in the control group at all time-points. Although the recovery and extubation times were longer in the lidocaine group than those in the control group, the RSS score was not significantly different between the two groups after extubation. A probable reason for this was that the patients in the lidocaine group were more tolerant to catheter stimulation, but it did not affect the sobriety after extubation. The haemodynamics of the patients in the lidocaine group were more consistent at the time of extubation and during the recovery period, and the patients also felt more comfortable. This may be due to the sedative, analgesic and stress-reducing effects of lidocaine $(29,38)$.

The half-life of lidocaine is 1.5-2.0 $\mathrm{h}$ with continuous intravenous infusion. A previous study by Koppert et al (39) indicated that the analgesic effect of intravenous lidocaine lasted for almost $72 \mathrm{~h}$ after the surgery. The present study indicated that continuous infusion of lidocaine is able to significantly relieve post-operative pain, and the greatest difference in pain was observed between 12 and $42 \mathrm{~h}$ after surgery. This may occur due to the pain of endoscopic surgery being relatively less than that associated with invasive surgery, and the greatest pain had passed at 2 days after the surgery. In addition, most patients refused to endure the acute pain and requested post-operative analgesia in the preliminary experiment. In order to enhance the comfort level of patients and reduce doctor-patient disputes, patients in two groups were intravenously given flurbiprofen axetil $(1 \mathrm{mg} / \mathrm{kg}$ ) for post-operative analgesia at the end of the operation (40). The half-life of flurbiprofen axetil is $\sim 5.8 \mathrm{~h}$ (41), and therefore, the pain within the first $6 \mathrm{~h}$ after the operation was not evaluated. This is also a shortcoming of the present study. Therefore, it is necessary to further investigate the analgesic effect of lidocaine on the acute pain period within $6 \mathrm{~h}$ after surgery.

The damage of intestinal function after surgery is associated with post-operative systemic inflammatory responses. A previous study by Kuo et al (42) indicated that intravenous lidocaine may reduce pro-inflammatory factors and is beneficial to the recovery of intestinal function. Furthermore, stimuli including intra-operative traction and pneumoperitoneal pressure may activate the intestinal nerve plexus, leading to injury of intestinal function. Intravenous lidocaine may excite the intestinal smooth muscle by blocking the mesenteric plexus and is beneficial to the recovery of intestinal function (14). In the present study, the first flatus and defecation times were earlier in the lidocaine group than they were in the control group, indicating that lidocaine is helpful in the early recovery of intestinal function.

The results of the present study suggested that the incidence of PONV was significantly lower in the lidocaine group than that in the control group, and the severity PONV was also significantly reduced. This may be due to the following factors: Improvement of the senses of patients during the recovery period from anaesthesia, reduction of the use of opioid agents, maintenance of haemodynamic stability during the peri-operative stage, reduction of post-operative pain and promotion of the early recovery of the gastrointestinal tract. However, the mechanism by which lidocaine prevents PONV remains elusive.

QOR40 is an effective, reliable and simple scale used to evaluate the quality of the post-operative recovery of patients. It has been successfully used to assess the quality of post-operative recovery in different patients and after different types of surgery, including heart surgery, laparoscopic gallbladder surgery and joint replacement surgery (43-45). The present study indicated that the recovery quality was much better in the lidocaine group than that in the control group at 1 and 3 days after surgery. However, the recovery quality was not significantly different between the groups at 5 days after surgery. Therefore, intravenous lidocaine may accelerate the early recovery of patients undergoing endoscopic gynaecological surgery. This promotion of early recovery may be associated with the beneficial effects of lidocaine mentioned above. However, the definite duration and efficiency of the promotion of post-operative recovery by lidocaine remain elusive. In addition, in the present study, patients with small surgical trauma, short operation times and good general health were selected. Therefore, further studies are required to determine whether lidocaine has the same effect on patients with comparatively greater surgical trauma, longer operation times and poor general health.

In conclusion, intravenous lidocaine used in patients undergoing laparoscopic gynaecological surgery may safely and effectively prevent PONV, and it may promote patients' early recovery, thus making it worthwhile to increase the use of lidocaine in the clinical setting. 


\section{Acknowledgements}

Not applicable.

\section{Funding}

No funding was received.

\section{Availability of data and materials}

The datasets used and/or analysed during the present study are available from the corresponding author on reasonable request.

\section{Authors' contributions}

YJZ conceived the study and revised the manuscript. TW wrote the manuscript. HL processed and analysed the data, and was involved in designing the study. TW, LW and HJS performed the experiments and collected the data. All authors read and approved the final manuscript.

\section{Ethics approval and consent to participate}

The present study was approved by the ethics committee of the Affiliated Hospital of Yangzhou University (Yangzhou, China) and all subjects provided written informed consent.

\section{Patient consent for publication}

Not applicable.

\section{Competing interests}

The authors declare that they have no competing interests.

\section{References}

1. Buia A, Stockhausen F and Hanisch E: Laparoscopic surgery: A qualified systematic review. World J Methodol 5: 238-254, 2015

2. Gan TJ: Risk factors for postoperative nausea and vomiting. Anesth Analg 102: 1884-1898, 2006.

3. Franck M, Radtke FM, Apfel CC, Kuhly R, Baumeyer A, Brandt C, Wernecke KD and Spies CD: Documentation of post-operative nausea and vomiting in routine clinical practice. J Int Med Res 38: 1034-1041, 2010.

4. Choi DH, Ko JS, Ahn HJ and Kim JA: A Korean predictive model for postoperative nausea and vomiting. J Korean Med Sci 20: 811-815, 2005.

5. Apfel CC, Heidrich FM, Jukar-Rao S, Jalota L, Hornuss C, Whelan RP, Zhang K and Cakmakkaya OS: Evidence-based analysis of risk factors for postoperative nausea and vomiting. $\mathrm{Br}$ J Anaesth 109: 742-753, 2012.

6. Wu O, Belo SE and Koutsoukos G: Additive antiemetic efficacy of prophylactic ondansetron with droperidol in out-patient gynecological laparoscopy. Can J Anaesth 47: 529-536, 2000.

7. Achuthan S, Singh I, Varthya SB, Srinivasan A, Chakrabarti A and Hota D: Gabapentin prophylaxis for postoperative nausea and vomiting in abdominal surgeries: A quantitative analysis of evidence from randomized controlled clinical trials. Br J Anaesth 114: 588-597, 2015.

8. Apfel CC: Postoperative nausea and vomiting. In: Miller's anesthesia. 7th edition. Miller RD (ed). Churchill Livingstone, Philadelphia, PA, pp2729-2755, 2010.

9. Swaika S, Pal A, Chatterjee S, Saha D and Dawar N: Ondansetron, ramosetron, or palonosetron: Which is a better choice of antiemetic to prevent postoperative nausea and vomiting in patients undergoing laparoscopic cholecystectomy? Anesth Essays Res 5: 182-186, 2011.
10. Shaikh SI, Nagarekha D, Hegade G and Marutheesh M: Postoperative nausea and vomiting: A simple yet complex problem. Anesth Essays Res 10: 388-396, 2016.

11. Herminghaus A, Wachowiak M, Wilhelm W, Gottschalk A, Eggert K and Gottschalk A: Intravenous administration of lidocaine for perioperative analgesia. Review and recommendations for practical usage. Anaesthesist 60: 152-160, 2011 (In German).

12. Jendoubi A, Naceur IB, Bouzouita A, Trifa M, Ghedira S, Chebil $\mathrm{M}$ and Houissa M: A comparison between intravenous lidocaine and ketamine on acute and chronic pain after open nephrectomy: A prospective, double-blind, randomized, placebo-controlled study. Saudi J Anaesth 11: 177-184, 2017.

13. Weibel S, Jokinen J, Pace NL, Schnabel A, Hollmann MW, Hahnenkamp K, Eberhart LH, Poepping DM, Afshari A and Kranke P: Efficacy and safety of intravenous lidocaine for postoperative analgesia and recovery after surgery: A systematic review with trial sequential analysis. Br J Anaesth 116: 770-783, 2016.

14. Tikuišis R, Miliauskas P, Samalavičius NE, Žurauskas A, Samalavičius R and Zabulis V: Intravenous lidocaine for post-operative pain relief after hand-assisted laparoscopic colon surgery: A randomized, placebo-controlled clinical trial. Tech Coloproctol 18: 373-380, 2014.

15. McKay A, Gottschalk A, Ploppa A, Durieux ME and Groves DS: Systemic lidocaine decreased the perioperative opioid analgesic requirements but failed to reduce discharge time after ambulatory surgery. Anesth Analg 109: 1805-1808, 2009.

16. Kaba A, Laurent SR, Detroz BJ, Sessler DI, Durieux ME, Lamy ML and Joris JL: Intravenous lidocaine infusion facilitates acute rehabilitation laparoscopic colectomy. Anesthesiology 106: 11-18, 2007.

17. Lauwick S, Kim DJ, Mistraletti G and Carli F: Functional walking capacity as an outcome measure of laparoscopic prostatectomy: The effect of lidocaine infusion. Br J Anaesth 103: 213-219, 2009

18. Lauwick S, Kim DJ, Michelagnoli G, Mistraletti G, Feldman L, Fried $\mathrm{G}$ and Carli F: Intraoperative infusion of lidocaine reduces postoperative fentanyl requirements in patients undergoing laparoscopic cholecystectomy. Can J Anaesth 55: 754-760, 2008.

19. Grady MV, Mascha E, Sessler DI and Kurz A: The effect of perioperative intravenous lidocaine and ketamine on recovery after abdominal hysterectomy. Anesth Analg 115: 1078-1084, 2012.

20. Myles PS, Weitkamp B, Jones K, Melick J and Hensen S: Validity and reliability of a postoperative quality of recovery score: The QoR-40. Br J Anaesth 84: 11-15, 2000.

21. Gornall BF, Myles PS, Smith CL, Burke JA, Leslie K, Pereira MJ, Bost JE, Kluivers KB, Nilsson UG, Tanaka Y and Forbes A: Measurement of quality of recovery using the QoR-40: A quantitative systematic review. Br J Anaesth 111: 161-169, 2013.

22. Aronson WL, McAuliffe MS and Miller K: Variability in the American society of anesthesiologists physical status classification scale. AANA J 71: 265-274, 2003.

23. Ramsay MA, Savege TM, Simpson BR and Goodwin R: Controlled sedation with alphaxalone-alphadolone. Br Med J 2: 656-659, 1974

24. Carlsson AM: Assessment of chronic pain. I. Aspects of the reliability and validity of the visual analogue scale. Pain 16: 87-101, 1983.

25. Eberhart LH, Seeling W, Ulrich B, Morin AM and Georgieff M: Dimenhydrinate and metoclopramide alone or in combination for prophylaxis of PONV. Can J Anaesth 47: 780-185, 2000.

26. Phillips C, Brookes CD, Rich J, Arbon J and Turvey TA: Postoperative nausea and vomiting following orthognathic surgery. Int J Oral Maxillofac Surg 44: 745-751, 2015.

27. Sinclair DR, Chung F and Mezei G: Can postoperative nausea and vomiting be predicted? Anesthesiology 91: 109-118, 1999.

28. Cardoso FC and Lewis RJ: Sodium channels and pain: From toxins to therapies. Br J Pharmacol 175: 2138-2157, 2018.

29. Lauretti GR: Mechanisms of analgesia of intravenous lidocaine. Rev Bras Anestesiol 58: 280-286, 2008 (In English).

30. Nakhli MS, Kahloul M, Guizani T, Zedini C, Chaouch A and Naija W: Intravenous lidocaine as adjuvant to general anesthesia in renal surgery. Libyan J Med 13: 1433418, 2018.

31. Kalso E: Sodium channel blockers in neuropathic pain. Curr Pharm Des 11: 3005-3011, 2005.

32. Kawamata M, Sugino S, Narimatsu E, Yamauchi M, Kiya T, Furuse S and Namiki A: Effects of systemic administration of lidocaine and QX-314 on hyperexcitability of spinal dorsal horn neurons after incision in the rat. Pain 122: 68-80, 2006. 
33. Hahnenkamp K, Durieux ME, Hahnenkamp A, Schauerte SK, Hoenemann CW, Vegh V, Theilmeier G and Hollmann MW: Local anaesthetics inhibit signalling of human NMDA receptors recombinantly expressed in Xenopus laevis oocytes: Role of protein kinase C. Br J Anaesth 96: 77-87, 2006.

34. Sugimoto M, Uchida I and Mashimo T: Local anaesthetics have different mechanisms and sites of action at the recombinant N-methyl-D aspartate (NMDA) receptors. Br J Pharmacol 138: 876-882, 2003

35. Yousefshahi F, Predescu O and Asenjo JF: The efficacy of systemic lidocaine in the management of chronic pain: A literature review. Anesth Pain Med 7: e44732, 2017.

36. Yardeni IZ, Beilin B, Mayburd E, Levinson Y and Bessler H: The effect of perioperative intravenous lidocaine on postoperative pain and immune function. Anesth Analg 109: 1464-1469, 2009.

37. Hans GA, Lauwick SM, Kaba A, Bonhomme V, Struys MM, Hans PC, Lamy ML and Joris JL: Intravenous lidocaine infusion reduces bispectral index-guided requirements of propofol only during surgical stimulation. Br J Anaesth 105: 471-479, 2010.

38. Ahn E, Kang H, Choi GJ, Park YH, Yang SY, Kim BG and Choi SW: Intravenous lidocaine for effective pain relief after a laparoscopic colectomy: A prospective, randomized, double-blind, placebo-controlled study. Int Surg 100: 394-401, 2015.

39. Koppert W, Weigand M, Neumann F, Sittl R, Schuettler J, Schmelz $\mathrm{M}$ and Hering W: Perioperative intravenous lidocaine has preventive effects on postoperative pain and morphine consumption after major abdominal surgery. Anesth Analg 98: 1050-1055, 2004.
40. Zhang J, Zhang H, Zhao L, Gu J, Feng Y and An H: Population pharmacokinetic modeling of flurbiprofen, the active metabolite of flurbiprofen axetil, in Chinese patients with postoperative pain. J Pain Res 11: 3061-3070, 2018.

41. Fujii Y and Itakura M: Comparison of lidocaine, metoclopramide, and flurbiprofen axetil for reducing pain on injection of propofol in Japanese adult surgical patients: A prospective, randomized, double-blind, parallel-group, placebo-controlled study. Clin Ther 30: 280-286, 2008.

42. Kuo CP, Jao SW, Chen KM, Wong CS, Yeh CC, Sheen MJ and Wu CT: Comparison of the effects of thoracic epidural analgesia and i.v. infusion with lidocaine on cytokine response, postoperative pain and bowel function in patients undergoing colonic surgery. Br J Anaesth 97: 640-646, 2006.

43. Myles PS, Hunt JO, Fletcher H, Solly R, Woodward D and Kelly S: Relation between quality of recovery in hospital and quality of life at 3 months after cardiac surgery. Anesthesiology 95: 862-867, 2001.

44. Murphy GS, Szokol JW, Greenberg SB, Avram MJ, Vender JS, Nisman M and Vaughn J: Preoperative dexamethasone enhances quality of recovery after laparoscopic cholecystectomy: Effect on in-hospital and postdischarge recovery outcomes. Anesthesiology 114: 882-890, 2011.

45. Poitras S, Beaule PE and Dervin GF: Validity of a short-term quality of life questionnaire in patients undergoing joint replacement: The quality of recovery-40. J Arthroplasty 27: 1604-1608, 2012. 